\title{
Synthesis and Characterization of Copper lons Doped Octacalcium Phosphate Powders with Enhanced Osteogenic Property
}

\author{
Jiwen Chen ${ }^{1}$, Changshun $\mathrm{Chen}^{3}$, Yunjun $\mathrm{Wu}^{1}$, Riwang $\mathrm{Li}^{1}$, Youjie Liu ${ }^{1}$, Yiwan $\mathrm{Shi}^{1}$, Huige Hou ${ }^{1}$, \\ Junting Liu ${ }^{4}$, Huajun Wang ${ }^{1, *}$, Tingting $\mathrm{Wu}^{2,}$, Xiaofei Zheng ${ }^{1, *}$ \\ ${ }^{1}$ Institute of Orthopedic Diseases and Center for Joint Surgery and Sports Medicine, The First Affiliated Hospital, Jinan University, Guangzhou, \\ P. R. China \\ ${ }^{2}$ National Engineering Research Center for Healthcare Devices, Guangdong Key Lab of Medical Electronic Instruments and Polymer Material \\ Products, Institute of Medicine and Health, Guangdong Academy of Sciences, Guangzhou, P. R. China \\ ${ }^{3}$ Gastrointestinal Surgery, The First Affiliated Hospital, Jinan University, Guangzhou, P. R. China \\ ${ }^{4}$ Department of Orthopaedic Trauma and Hand Surgery, The First Affiliated Hospital of Guangxi Medical University, Nanning Guangxi, P. R. \\ China
}

\section{Email address:}

doctorzhengxiaofei@hotmail.com (Xiaofei Zheng),wtt_08@126.com (Tingting Wu),whj323@126.com (Huajun Wang)

${ }^{*}$ Corresponding author

\section{To cite this article:}

Jiwen Chen, Changshun Chen, Yunjun Wu, Riwang Li, Youjie Liu, Yiwan Shi, Huige Hou, Junting Liu, Huajun Wang, Tingting Wu, Xiaofei Zheng. Synthesis and Characterization of Copper Ions Doped Octacalcium Phosphate Powders with Enhanced Osteogenic Property. Journal of Biomaterials. Vol. 5, No. 1, 2021, pp. 10-15. doi: 10.11648/j.jb.20210501.12

Received: March 27, 2021; Accepted: April 12, 2021; Published: April 16, 2021

\begin{abstract}
Diverse biomaterials have been designed to promote bone regeneration, and due to their potential side effects of adverse inflammation and immune responses, only a few synthetic biomaterials displayed successful clinical outcomes in repairing bone defects. The repair of bone defects remains a big challenge for orthopedists. This study was dedicated to the synthesis of copper-doped octacalcium phosphate powder $\mathrm{Cu}-\mathrm{OCP}$ with good bone repair potential, which provides a new way for the construction of bone regeneration biomaterials. Five kinds of copper-doped powders, OCP, 0.1Cu-OCP, $0.5 \mathrm{Cu}-\mathrm{OCP}, \mathrm{Cu}-\mathrm{OCP}$ and $5 \mathrm{Cu}-\mathrm{OCP}$, were synthesized by chemical homogeneous precipitation method. The phases of the powders were analyzed by X-ray diffraction (XRD). The elemental compositions of the powders were analyzed by X-ray fluorescence spectrometer (XRF). The microstructures of the powders were observed by scanning electron microscopy (SEM). Inductively coupled plasma atomic emission spectrometry (ICP) was used to determine the 24-hour cumulative release of copper ions in Tris solution. The biocompatibility of the powders was measured by CCK8 and live/dead staining. The effect of the powders on bone differentiation was measured by ALP activity. the OCP powder was a long strip chip like crystal structure under SEM. The doping of $\mathrm{Cu}^{2+}$ made the chip structure smaller and finer. The main diffraction peak of OCP can be seen at $2 \theta=4.7^{\circ}$ for all the five powders. XRF showed that the main composition of the powders was still Ca, $\mathrm{P}$ and $\mathrm{O}$. The mass fractions of $\mathrm{Cu}^{2+}$ in the powders were $0.1 \mathrm{Cu}-\mathrm{OCP}: 0.02 \%, 0.5 \mathrm{Cu}-\mathrm{OCP}: 0.08 \%, \mathrm{Cu}-\mathrm{OCP}: 0.23 \%$, and 5Cu-OCP: $0.76 \%$, respectively. ICP results showed that $\mathrm{Ca}, \mathrm{P}$ and $\mathrm{Cu}$ were released slowly in 24 hours in Tris solution. CCK8 and live/dead staining showed that all kinds of copper-doped OCP powders had good biocompatibility with mBMSCs, and could promote osteogenic differentiation. Among them, 0.5Cu-OCP promoted the proliferation and ALP activity of mBMSCs significantly. In conclusion, in this study, copper ions were successfully doped into OCP powder, and the physical and chemical properties of OCP powders doped with copper ions were characterized. In vitro cell experiment confirmed that the powders had good biocompatibility, non-toxic to mBMSCs, and could promote the proliferation of mBMSCs in vitro.
\end{abstract}

Keywords: Octacalcium Phosphate, Copper Ions, Osteogenesis, Bone Regeneration 


\section{Introduction}

Bone tissue engineering (BTE) strategy has rapidly developed over the last recent decades [1]. Diverse biomaterials have been designed to promote bone regeneration, and due to their potential side effects of adverse inflammation and immune responses, only a few synthetic biomaterials displayed successful clinical outcomes in repairing bone defects [2]. The repair of bone defects remains a big challenge for orthopedists.

Octacalcium phosphate (OCP) is one of the precursors of bone and dental apatite minerals [3], which plays an important role in the formation of bone minerals and initial intramembrane osteogenesis [4]. OCP has better bone conductivity, biodegradability and bioactivity than hydroxyapatite (HA) [5-6]. After implantation, OCP has no stimulation and rejection effect on the tissue, and can form a strong chemical binding with bone. Compared with tricalcium phosphate (TCP), OCP can degrade faster, so it is a good material for bone defect regeneration and repair [7]. OCP can also be used as a carrier of bisphosphate for bone repair after bone tumor removal [8].

Copper is not only an indispensable cofactor of enzyme and nonenzyme dependent copper protein in mitochondrial respiration, neurotransmitter synthesis, peptide amidation, connective tissue formation, iron metabolism and other processes [9-11], but also the production of collagen and elastin depends on the activation and participation of copper [12]. Bone minerals contain magnesium, zinc, copper, manganese and other trace elements. Doping these bioactive ions into inorganic bioceramics can simulate the composition of bone and promote the formation of new bone by releasing these trace elements [13-14]. In recent years, copper ions have been widely used in the field of bone and vascular tissue repair [15]. However, the application of copper in bone repair is rarely reported. In this study, copper-doped $\mathrm{OCP}(\mathrm{Cu}-\mathrm{OCP})$ powder was synthesized by copper ion doping in OCP, which was expected to further strengthen the osteogenesis of OCP, and provide a new idea for the application of trace elements in tissue engineering and bone repair biomaterial.

\section{Materials and Methods}

\subsection{Synthesis of OCP and Cu-OCP Powder}

OCP and copper-doped OCP were synthesized by the classical chemical homogeneous precipitation method. Copper in $\mathrm{Cu}-\mathrm{OCP}$ was supplied by copper acetate. The basic steps were as follow:

For the synthesis of OCP, calcium acetate monohydrate (Tianjin Kemiou Chemical Reagent Co., Ltd, China) calculated by concentration and $300 \mathrm{~mL}$ deionized water were fully stirred to form solution A. For the synthesis of copper-doped OCP, 250 $\mathrm{mL}$ calcium acetate aqueous solution and $50 \mathrm{~mL}$ copper acetate (Tianjin Fortune Chemical Reagent Factory, China) solution calculated by concentration were stirred to form solution A. Then, $30 \mathrm{mM}$ ammonium dihydrogen phosphate (Guangzhou Chemical Reagent Factory, China) and $100 \mathrm{mM}$ urea
(Guangzhou Chemical Reagent Factory, China) were added to $300 \mathrm{~mL}$ deionized water to form solution B. Both solution A and solution B were stirred until dissolved, respectively. Under the condition of stirring, solution A was slowly dripped into solution B gradually within 5 minutes at room temperature. Then it was transferred to a constant temperature water bath at $90^{\circ} \mathrm{C}$ and stirred at $750 \mathrm{rpm}$ for 4 hours. In the process of dissolution, the stoichiometry of $\mathrm{Cu}$ was equal to the concentration of $\mathrm{Cu}$ doped in solution $\mathrm{A}$, and the stoichiometry of $(\mathrm{Cu}+\mathrm{Ca}) / \mathrm{P}$ was maintained to 1.33 . The concentrations of copper ions doped into the OCP powders were designed with five gradients of $0 \%, 0.1 \%, 0.5 \%, 1 \%$ and $5 \%$. The corresponding powders were expressed as $\mathrm{OCP}, 0.1 \mathrm{Cu}-\mathrm{OCP}$, $0.5 \mathrm{Cu}-\mathrm{OCP}, \mathrm{Cu}-\mathrm{OCP}$ and $5 \mathrm{Cu}-\mathrm{OCP}$. The reactant precipitation was first washed with deionized water for 3 times followed by ethanol for 2 times at $4500 \mathrm{rpm}$ for 10 minutes. Finally, the obtained precipitations were dried in an oven at $37^{\circ} \mathrm{C}$.

\subsection{Characterizations of the Synthesized Powders}

\subsubsection{XRD}

Polycrystalline X-Ray Diffractometers (XRD, D8 Advance, Bruker, Switzerland) was used to detect the phase of the substance.

\subsection{2. $X R F$}

X-ray fluorescence spectrometer (XRF, 3600, Thermo Fisher Scientific, USA) was used to analyze the element composition in the fabricated powder.

\subsubsection{SEM}

Scanning electron microscope (SEM, 4006-800-720, ZEISS, Germany) was used to observe the micro-structure of OCP powders.

\subsubsection{Ions Release}

Five kinds of powders $\mathrm{OCP}, 0.1 \mathrm{Cu}-\mathrm{OCP}, 0.5 \mathrm{Cu}-\mathrm{OCP}$, $\mathrm{Cu}-\mathrm{OCP}$ and $5 \mathrm{Cu}-\mathrm{OCP}$ were added to $10 \mathrm{~mL}$ Tris solution $(0.05 \mathrm{mmol} / \mathrm{mL}, \mathrm{PH} 10.02)$ respectively and Shaken at the speed of $72 \mathrm{rpm}$ in a $37^{\circ} \mathrm{C}$ Shaker for 24 hours followed by centrifugation at the speed of $8000 \mathrm{rpm}$. The supernatant was filtered and 10 times diluted. And $10 \mathrm{~mL}$ copper acetate solution with the concentration of $10 \mu \mathrm{mol} / \mathrm{L}$ was prepared as control. The accumulated concentrations of copper, phosphorus and calcium in the samples were determined by Inductively coupled plasma atomic emission spectrometer (ICP-AES; Optimal 5300DV, Perkin Elmer, USA).

\subsection{Biocompatibility and Bone Regeneration Potential of the Powders}

\subsubsection{CCK8 Assay and Live/Dead Staining}

The powders were sterilized under high pressure, then 0.05 $\mathrm{mg} / \mathrm{mL}$ powder culture medium (including $10 \% \mathrm{FBS}, 1 \%$ sodium pyruvate, $1 \%$ Penicillin-Streptomycin and $88 \%$ DMEM) was prepared. The mouse bone marrow stromal cells (mBMSCs) of P5 generation were seeded into 48-well plates at the density of $5 \times 10^{3} /$ well. After 24 hours, $500 \mu \mathrm{L}$ of the 
powder culture medium was added into each well, and the control group was added with culture medium without any of the powder. The solution was changed with pure culture medium every other day. CCK8 and live/dead staining were performed on Day $1 / 3 / 5$ to analyze the cell proliferation.

\subsubsection{ALP Activity}

The mouse bone marrow stromal cells (mBMSCs) of P5 generation were seeded into 48 -well plates at the density of $5 \times 10^{4} /$ well. After 24 hours, $500 \mu \mathrm{L}$ of the powder culture medium was added into each well, and the control group was added with culture medium without any of the powder. The solution was changed with Osteoinductive fluid (culture medium with $10 \mathrm{mM}$ Sodium glycerophosphate, $1 \times 10^{-8} \mathrm{mM}$ dexamethasone, and $50 \mathrm{mg} / \mathrm{L}$ ascorbic acid) every other day. ALP activity was determined on day 7 and 14 .

\section{Results}

\subsection{XRD}

The main diffraction peaks of the XRD near $4.7^{\circ}$ indicated that all the synthesized powders were well-crystallized OCP and corresponded to JCPDS PDF\#26-1056, but the main diffraction peaks value decreased as copper doped into the OCP powders. The diffraction peak (010) and (700) were also observed near $9.3^{\circ}$ and $33.5^{\circ}$. The results show that the doping of copper didn't change the phase of OCP, and the increase of copper content decreased the peak of OCP slightly (Figure 1).

Table 1. X-ray fluorescence spectrometric analysis of five copper-doped powders.

\begin{tabular}{|c|c|c|c|}
\hline Compound & $\begin{array}{l}\text { Element contained } \\
\text { in } O C P \text { or } \mathrm{Cu}-\mathrm{OCP}\end{array}$ & $\begin{array}{l}\text { Molar fraction } \\
(\%)\end{array}$ & $\begin{array}{l}\mathrm{Ca} / \mathrm{P} \text { molar } \\
\text { ratio }\end{array}$ \\
\hline \multirow{4}{*}{ OCP } & $\mathrm{Ca}$ & 21.54 & \multirow{4}{*}{1.33} \\
\hline & $\mathrm{P}$ & 16.18 & \\
\hline & $\mathrm{O}$ & 61.99 & \\
\hline & Others & 0.29 & \\
\hline \multirow{5}{*}{$0.1 \mathrm{Cu}-\mathrm{OCP}$} & $\mathrm{Ca}$ & 20.59 & \multirow{5}{*}{1.23} \\
\hline & $\mathrm{P}$ & 16.69 & \\
\hline & $\mathrm{O}$ & 62.53 & \\
\hline & $\mathrm{Cu}$ & 0.02 & \\
\hline & Others & 0.17 & \\
\hline \multirow{5}{*}{$0.5 \mathrm{Cu}-\mathrm{OCP}$} & $\mathrm{Ca}$ & 20.63 & \multirow{5}{*}{1.25} \\
\hline & $\mathrm{P}$ & 16.53 & \\
\hline & $\mathrm{O}$ & 62.27 & \\
\hline & $\mathrm{Cu}$ & 0.08 & \\
\hline & Others & 0.50 & \\
\hline \multirow{5}{*}{$\mathrm{Cu}-\mathrm{OCP}$} & $\mathrm{Ca}$ & 20.09 & \multirow{5}{*}{1.19} \\
\hline & $\mathrm{P}$ & 16.89 & \\
\hline & $\mathrm{O}$ & 62.67 & \\
\hline & $\mathrm{Cu}$ & 0.13 & \\
\hline & Others & 0.22 & \\
\hline \multirow{5}{*}{$5 \mathrm{Cu}-\mathrm{OCP}$} & $\mathrm{Ca}$ & 20.93 & \multirow{5}{*}{1.30} \\
\hline & $\mathrm{P}$ & 16.07 & \\
\hline & $\mathrm{O}$ & 62.04 & \\
\hline & $\mathrm{Cu}$ & 0.76 & \\
\hline & Others & 0.20 & \\
\hline
\end{tabular}

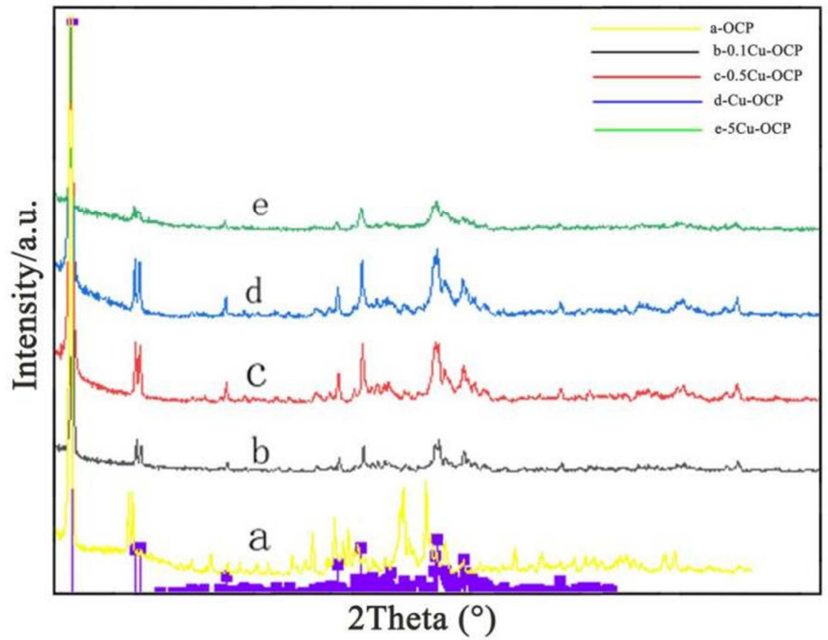

Figure 1. XRD pattern of the five kinds of OCP powders doped with different content of copper.

\section{2. $X R F$}

As shown in Table 1, the XRF results showed that the five copper-doped OCP powders were still mainly composed of $\mathrm{Ca}, \mathrm{P}$ and $\mathrm{O}$, and the molar fraction of copper in the powders were $0.1 \mathrm{Cu}-\mathrm{OCP}: 0.02 \%, 0.5 \mathrm{Cu}-\mathrm{OCP}: 0.08 \%$, Cu-OCP: $0.23 \%$, and $5 \mathrm{CU}-\mathrm{OCP}: 0.76 \%$, respectively. It was indicated that with the increase of the doping concentration of copper, the molar fraction of copper in each powder also increased, but overall, the proportion of copper was very little.

\subsection{SEM}

The crystal structure of five kinds of powders was long strip flake like wood chips under SEM. The copper-doped OCP crystal structure became smaller and finer with the increasing of copper content. When the copper content reached $5 \%$, the crystal structure of $5 \mathrm{Cu}-\mathrm{OCP}$ powder was very fine (Figure 2).

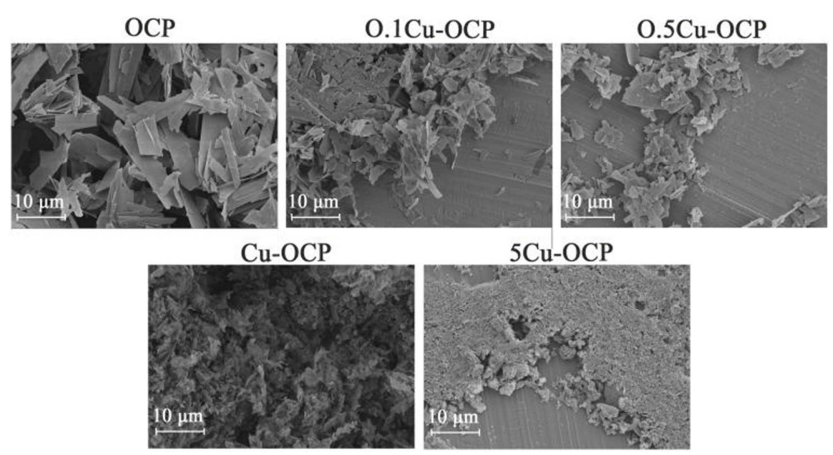

Figure 2. SEM images of five different copper-doped OCP powders.

\subsection{Ions Release}

The results of ICP showed that the concentrations of Ca, P and $\mathrm{Cu}$ released by 5 kinds of powders after 24 hours in Tris solution were shown in Table 2. It was indicated that the copper ions released from various copper-doped powders in 24 hours were trace, and copper ions were slowly released in 
the Tris liquid environment after being doped into OCP.

Table 2. ICP determination of $\mathrm{Ca}, \mathrm{P}$ and $\mathrm{Cu}$ ions released from powders.

\begin{tabular}{llll}
\hline \multirow{2}{*}{ Compounds } & \multicolumn{3}{l}{ Average concentration (ppm) } \\
\cline { 2 - 4 } Ca & P & Cu \\
\hline OCP $(1 \mathrm{mg} / \mathrm{mL})$ & 0.013 & 0.003 & 0.527 \\
$0.1 \mathrm{Cu}-\mathrm{OCP}(1 \mathrm{mg} / \mathrm{mL})$ & 0.016 & 0.192 & 0.008 \\
$0.5 \mathrm{Cu}-\mathrm{OCP}(1 \mathrm{mg} / \mathrm{mL})$ & 0.012 & 0.178 & 0.027 \\
$\mathrm{Cu}-\mathrm{OCP}(1 \mathrm{mg} / \mathrm{mL})$ & 0.015 & 0.221 & 0.132 \\
$5 \mathrm{Cu}-\mathrm{OCP}(1 \mathrm{mg} / \mathrm{mL})$ & 0.014 & 1.313 & 0.285 \\
\hline
\end{tabular}

\subsection{CCK8 assay and Live/Dead Staining}

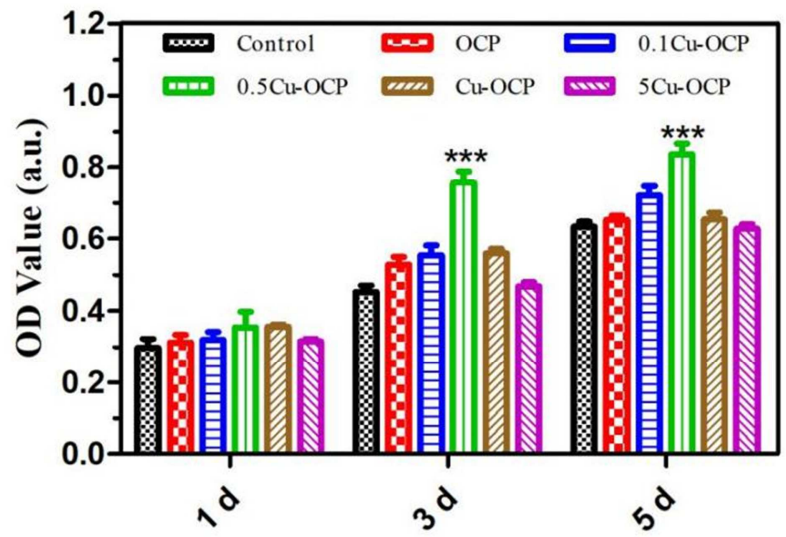

Figure 3. Five kinds of powders were cocultured with mBMSCs for 1, 3 and 5 days, the results of CCK-8 assays. ${ }^{* * *} p<0.001$, compared to the control group.
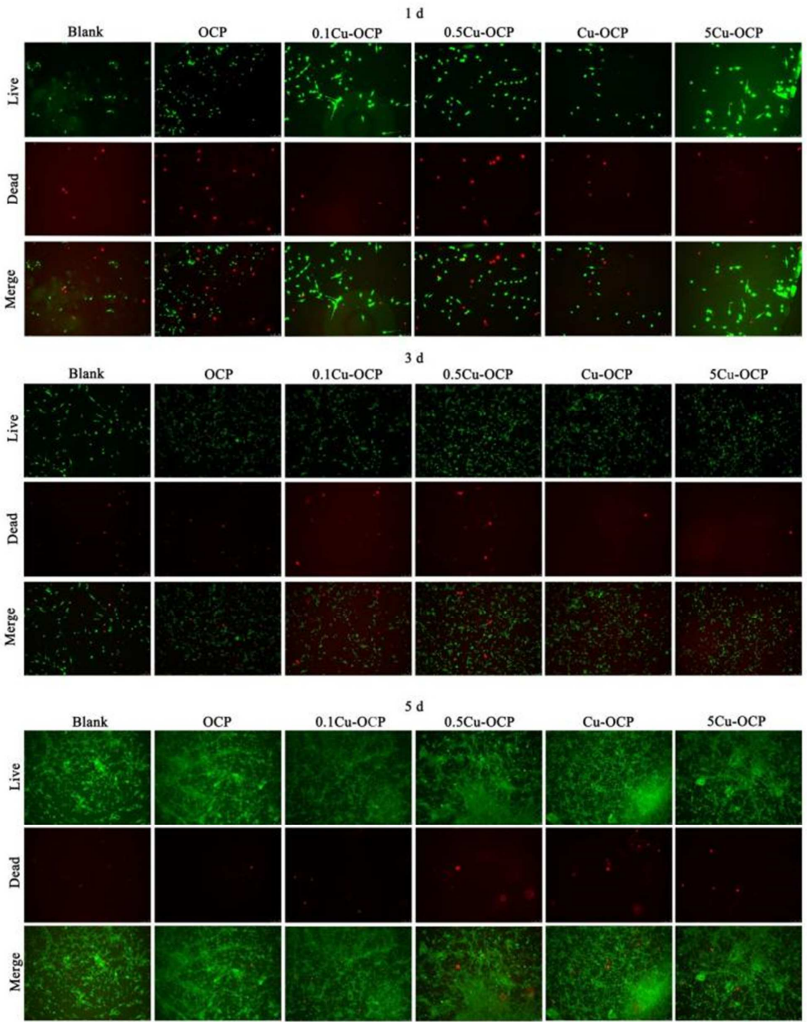

Figure 4. Five kinds of powders were cocultured with mBMSCs for 1, 3 and 5 days, the results of live/dead staining.
After mBMSCs were co-cultured with 5 kinds of powders for 1,3 and 5 days, the results of CCK- 8 showed that the OD values in each experimental group were higher than those in the control group, it was obvious on day 3 and 5, and significantly in group $0.5 \mathrm{Cu}-\mathrm{OCP}$ (Figure 3 ).

Similarly, live/dead staining showed that mBMSCs survived well with various copper-doped OCP powders. With the increase of time, the cells of each group proliferated steadily, and the proliferation of each experimental group was promoted compared to the control group, among which $0.5 \mathrm{Cu}-\mathrm{OCP}$ and $\mathrm{Cu}-\mathrm{OCP}$ Group were significantly promoted (Figure 4).

\subsection{ALP Activity}

The ALP activity was detected after 5 kinds of powders were cocultured with mBMSCs for 7 and 14 days. The ALP activity of mBMSCs increased over time. And it was significantly higher in group OCP, $0.1 \mathrm{Cu}-\mathrm{OCP}, 0.5 \mathrm{Cu}-\mathrm{OCP}$, and $\mathrm{Cu}-\mathrm{OCP}$ compared to the control group on the $14^{\text {th }}$ day, among which, group $0.5 \mathrm{Cu}-\mathrm{OCP}$, and $\mathrm{Cu}-\mathrm{OCP}$ were most obviously (Figure 5).

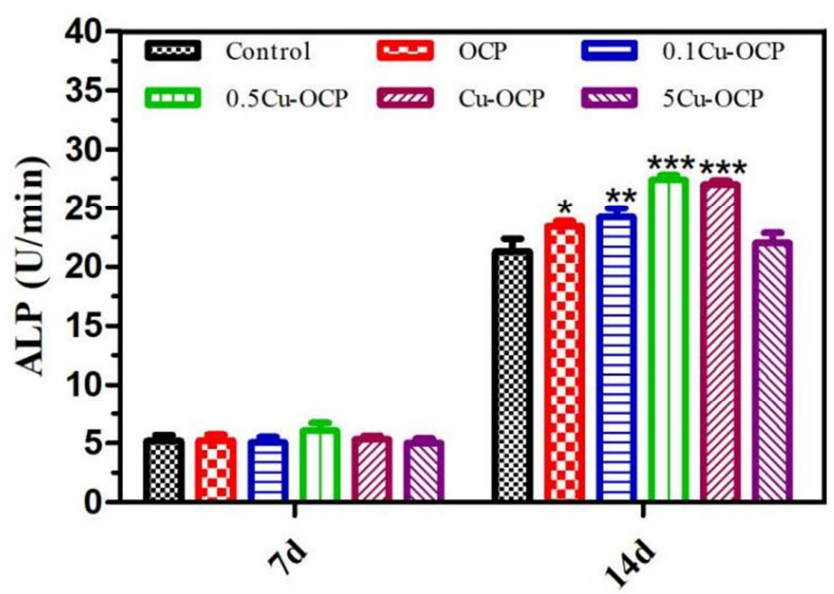

Figure 5. The ALP activity of mBMSCs was detected after 7 and 14 days cocultured with 5 kinds of powders. ${ }^{*} p<0.05,{ }^{* *} p<0.01,{ }^{* * *} P<0.001$, compared to the control group.

\section{Discussion}

As a precursor of bone and dental apatite minerals, OCP plays an important role in the formation of bone minerals and initial intramembrane osteogenesis, with good bone conductivity, biodegradability and bioactivity. After implantation, it has no stimulation and rejection to the tissue. It can form a strong chemical bond with bone and degrade faster than TCP. It is a good material for bone defect regeneration and repair [16]. Kouketsu A et al. [17] Fabricated two kinds of porous scaffolds, OCP/COL (composed of octacalcium phosphate and collagen) and TCP/COL (composed of tricalcium phosphate and collagen). Then, they implanted the scaffolds into the calvarial defects of Twelve - week - old male Wistar rats and fixed for 2 or 4 weeks. The results of radiographic and $\mu-\mathrm{CT}$ examination showed the regeneration of the calvarial defects much more 
better in the $\mathrm{OCP} / \mathrm{COL}$ group than that in the TCP/COL group. And all the osteogenic biomarkers expression, such as osteopontin, osteocalcin, Runt-related transcription factor 2, type 1 collagen, vascular endothelial growth factor, and ALP, were higher in the $\mathrm{OCP} / \mathrm{Col}$ group than in the TCP/COL group at 2 and 4 weeks after surgery. The experiment indicated that OCP exhibited good osteoconductive activity and osteoinductive capacity.

As a cofactor of enzyme and non-enzyme copper dependent protein, copper participates in mitochondrial respiration, neurotransmitter synthesis, peptide amidation, connective tissue formation and iron metabolism. Therefore, copper is an indispensable trace element in human body [18-20]. Based on the biological functions and benefits of copper, more and more biomaterial researchers are committed to developing new copper containing biomaterials, which have unique properties in protecting the cardiovascular system, promoting fracture healing, and playing antibacterial role. Copper can also be used to promote wound healing, kill cancer cells, positron emission tomography (PET) imaging, radio immunotherapy and cancer radiotherapy [21]. Copper has been widely used in repairing bone and vascular tissue [22]. Previous studies have shown that copper can promote the osteogenic differentiation, new bone formation and angiogenesis of BMSCs in vivo. Materials containing copper, such as copper stainless steel or copper-coated bioactive glass scaffolds, have been successfully developed for bone repair [23-28].

Therefore, doping copper ions into inorganic biomaterials and slowly releasing them from the materials are expected to better promote the formation of new bone. In this study, we successfully doped different concentrations of copper into OCP. XRD results showed that the doping of copper did not significantly change the phase of OCP. The increase of copper content could make the peak value of OCP decrease slightly. XRF showed that the main composition of copper-doped OCP powder were still $\mathrm{Ca}, \mathrm{P}$ and $\mathrm{O}$. And the molar fraction of copper in the powder was trace. The results of ICP showed that the copper ions released from copper-doped OCP powder in 24 hours was trace, which reflected that copper could be released slowly in Tris liquid environment after doping into OCP. The slow release of copper from the powder was the important theoretical basis for the nontoxicity of copper to mBMSCs in vitro and to the body in vivo. In this study, OCP and copper-doped OCP powders were cocultured with mBMSCs. CCK-8 and live/dead staining results showed that all the powders doped with copper and without copper had good biocompatibility, and $0.5 \mathrm{Cu}-\mathrm{OCP}$ powder could significantly promote the proliferation of mBMSCs.

ALP is an important marker of osteogenic differentiation [29]. In this study, the ALP activity of mBMSCs in OCP, $0.1 \mathrm{Cu}-\mathrm{OCP}, \quad 0.5 \mathrm{Cu}-\mathrm{OCP}$ and $\mathrm{Cu}-\mathrm{OCP}$ groups were significantly increased after 14 days of coculture, especially in $0.5 \mathrm{Cu}-\mathrm{OCP}$ group. The results showed that $0.5 \mathrm{Cu}-\mathrm{OCP}$ might promote the osteogenic differentiation of mBMSCs. Based on the fact that copper-doped OCP powders could significantly promote the proliferation and osteogenic differentiation of mBMSCs, it is expected to be used together with other organic materials such as silk fibroin and sodium alginate to prepare composite scaffolds to promote the repair of bone defects.

\section{Conclusion}

In this study, copper was successfully doped into the OCP powders, and the physical and chemical properties of the OCP powders doped with copper were characterized. In vitro cell experiments confirmed that the powder has good biocompatibility, and was non-toxic to mBMSCs, and could promote the proliferation of mBMSCs. In addition, it had the potential to promote the osteogenic differentiation of mBMSCs. The synthesis of the copper-doped powder is expected to introduce copper ions into the construction of bone repair biomaterials, which provides a new idea for the application of trace elements in bone repair research.

\section{Acknowledgements}

This study was supported by Special Fund Project for Guangdong Academy of Sciences to Build First Class Research Institutions in China (2019GDASYL-20210102), Guangzhou Science and Technology Program (201904010280), Guangdong Science and Technology Program (2018A050506056), the Natural Science Foundation of Guangdong Province (2019A1515011553), the Fundamental Research Funds for the Central Universities (21620452, 21619408).

\section{References}

[1] Amini AR, Laurencin CT, Nukavarapu SP: Bone tissue engineering: recent advances and challenges. Crit Rev Biomed Eng 2012, 40: 363-408.

[2] Campana V, Milano G, Pagano E, Barba M, Cicione C, Salonna G, Lattanzi W, Logroscino G: Bone substitutes in orthopaedic surgery: from basic science to clinical practice. J Mater Sci Mater Med 2014, 25 (10): 2445-61.

[3] Brown WE, Smith JP, Lehr JR, Frazier AW: Crystallographic and chemical relations between octacalcium phosphate and hydroxyapatite. Nature 1962, 196: 1050-5.

[4] T. Kurobane, Y. Shiwaku, T. Anada, R. Hamai, K. Tsuchiya, K. Baba, M. Iikubo, T. Takahashi, O. Suzuki: Angiogenesis involvement by octacalcium phosphate-gelatin composite-driven bone regeneration in rat calvaria critical-sized defect. Acta Biomaterialia 2019, 88: 514-526.

[5] Kamakura S, Sasano Y, Shimizu T, Hatori K, Suzuki O, Kagayama M: Implanted octacalcium phosphate is more resorbable than beta-tricalcium phosphate and hydroxyapatite. Journal of biomedical materials research 2002, 59 (1): 29-34.

[6] Habibovic P, van der Valk CM, van Blitterswijk CA, De Groot $\mathrm{K}$, Meijer G: Influence of octacalcium phosphate coating on osteoinductive properties of biomaterials. Journal of materials science Materials in medicine 2004, 15 (4): 373-80. 
[7] O. Suzuki, S. Kamakura, T. Katagiri, M. Nakamura, B. Zhao, Y. Honda, R. Kamijo: Bone formation enhanced by implanted octacalcium phosphate involving conversion into Ca-deficient hydroxyapatite. Biomaterials 2006, 27 (13): 2671-2681.

[8] L. Forte, P. Torricelli, E. Boanini, M. Gazzano, M. Fini, A. Bigi Antiresorptive and anti-angiogenetic octacalcium phosphate functionalized with bisphosphonates. An in vitro tri-culture study. Acta Biomaterialia 2017, 54: 419-428.

[9] M. Bost, S. Houdart, M. Oberli, E. Kalonji, J.-F. Huneau, I. Margaritis: Dietary copper and human health. Current evidence and unresolved issues. Trace Elem. Med Biol 2016, 35: 107-115.

[10] A. Robert, Y. Liu, M. Nguyen, B. Meunier: Regulation of Copper and Iron Homeostasis by Metal Chelators: A Possible Chemotherapy for Alzheimer's Disease. Acc. Chem Res 2015, 48 (5): 1332-1339.

[11] Y. Hatori, Y. Yan, K. Schmidt, E. Furukawa, N. M. Hasan, N. Yang, C.-N. Liu, S. Sockanathan, S. Lutsenko: Neuronal differentiation is associated with a redox-regulated increase of copper flow to the secretory pathway. Nature Communications 2016, 7: 10640 .

[12] T. Kosonen, J. Y. Uriu-Hare, M. S. Clegg, C. L. Keen, R. B. Rucker: Incorporation of copper into lysyl oxidase. The Biochemical journal 1997, 327 (1): 283-9.

[13] M. Shi, Z. Chen, S. Farnaghi, T. Friis, X. Mao, Y. Xiao, C. Wu: Copper-doped mesoporous silica nanospheres, a promising immunomodulatory agent for inducing osteogenesis. Acta Biomaterialia 2016, 30: 334-344.

[14] S. Meininger, S. Mandal, A. Kumar, J. Groll, B. Basu, U. Gbureck: Strength reliability and in vitro degradation of three-dimensional powder printed strontium-substituted magnesium phosphate scaffolds. Acta Biomaterialia 2016, 31 : 401-411.

[15] H. Hu, Y. Tang, L. Pang, C. Lin, W. Huang, D. Wang, W. Jia: Angiogenesis and Full Thickness Wound Healing Efficiency of a Copper-Doped Borate Bioactive Glass/Poly (lactic-co-glycolic acid) Dressing Loaded with Vitamin E in Vivo and in Vitro. ACS Applied Materials \& Interfaces 2018, 10 (27): 22939-22950.

[16] Suzuki O, Shiwaku Y, Hamai R: Octacalcium phosphate bone substitute materials: Comparison between properties of biomaterials and other calcium phosphate materials. Dent Mater J 2020, 39 (2): 187-199.

[17] Kouketsu A, Matsui K, Kawai T, Ezoe Y, Yanagisawa T, Yasuda A, Takahashi T, Kamakura S: Octacalcium phosphate collagen composite stimulates the expression and activity of osteogenic factors to promote bone regeneration. J Tissue Eng Regen Med 2020, 14 (1): 99-107.

[18] W. Yang, J. Wang, L. Liu, X. Zhu, X. Wang, Z. Liu, Z. Wang, L. Yang, G. Liu, Biol: Effect of High Dietary Copper on
Somatostatin and Growth Hormone-Releasing Hormone Levels in the Hypothalami of Growing Pigs. Trace Elem. Res 2011, 143: 893-900.

[19] A. Gajewska, B. Gajkowska, B. Pajak, J. Styrna, K. Kochman, Brain Res: Impaired growth hormone-releasing hormone neurons ultrastructure and peptide accumulation in the arcuate nucleus of mosaic mice with altered copper metabolism. Bull 2009, 80 (3): 128-132.

[20] J. R. Prohaska, A. A. Gybina, J: Intracellular Copper Transport in Mammals. Nutr 2004, 134 (5): 1003-1006.

[21] Wang P, Yuan Y, Xu K, Zhong H, Yang Y, Jin S, Yang K, Qi X: Biological applications of copper-containing materials. Bioact Mater 2020, 6 (4): 916-927.

[22] Xu D, Qian J, Guan X, Ren L, Yang K, Huang X, Zhang S, Chai Y, Wu X, Wu H, Zhang X, Yang K, Yu B: Copper-Containing Alloy as Immunoregulatory Material in Bone Regeneration via Mitochondrial Oxidative Stress. Front Bioeng Biotechnol 2021, 8: 620629 .

[23] L. Ren, H. M. Wong, C. H. Yan, K. W. Yeung, K. Yang, J: Osteogenic ability of Cu-bearing stainless steel. Biomed. Mater Res 2015, 103 (7): 1433-1444.

[24] C. Wu, Y. Zhou, M. Xu, P. Han, L. Chen, J. Chang, Y. Xiao: Copper-containing mesoporous bioactive glass scaffolds with multifunctional properties of angiogenesis capacity, osteostimulation and antibacterial activity. Biomaterials 2013, 34 (2): 422-433.

[25] Y. Lu, L. Li, Y. Zhu, X. Wang, M. Li, Z. Lin, X. Hu, Y. Zhang, Q. Yin, H. Xia: Multifunctional Copper-Containing Carboxymethyl Chitosan/Alginate Scaffolds for Eradicating Clinical Bacterial Infection and Promoting Bone Formation. ACS Appl. Mater. Interfaces 2018, 10 (1): 127-138.

[26] W. Zhang, Q. Chang, L. Xu, G. Li, G. Yang, X. Ding, X. Wang, D. Cui, $X$. Jiang: Graphene Oxide-Copper Nanocomposite-Coated Porous CaP Scaffold for Vascularized Bone Regeneration via Activation of Hif- $1 \alpha$. Adv. Healthcare Mater 2016, 5 (11): 1299-1309.

[27] Y. Lu, L. Li, Z. Lin, L. Wang, L. Lin, M. Li, Y. Zhang, Q. Li, H. Xia: A New Treatment Modality for Rheumatoid Arthritis: Combined Photothermal and Photodynamic Therapy Using Cu7.2S4 Nanoparticles. Adv. Healthcare Mater 2018, 7 (14): 1800013-1800023.

[28] P. M. Gomez, L. Fourcade, M. A. Mateescu: On some new species of AncorabolidaeSars, 1909 from the Gulf of California: the genera Ceratonotus Sars, 1909, and Dendropsyllus Conroy-Dalton, 2003 (Crustacea, Copepoda, Harpacticoida). J. Paquin, Anal. Biochem 2017, 535: 43-46.

[29] Serigano, K., Sakai, D., Hiyama, A., Tamura, F., Tanaka, M., \& Mochida, J: Effect of cell number on mesenchymal stem cell transplantation in a canine disc degeneration model. Journal of Orthopaedic Research 2010, 28 (10): 1267-75. 